\title{
HAEMODYNAMIC CONSEQUENCES IN IMMEDIATE POSTOPERATIVE PERIOD IN COMPARISON BETWEEN OPEN AND LAPAROSCOPIC CHOLECYSTECTOMY"
}

\author{
BANU $\mathrm{S}^{1}$, MONDOL MSH${ }^{2}$, DAS RS ${ }^{3}$, ALI MA ${ }^{4}$, SHATHI IJ ${ }^{5}$, KHATUN MH ${ }^{6}$, RAHMAN KM ${ }^{7}$
}

\begin{abstract}
:
Background: Laparoscopic cholecystectomy has emerged as a popular alternative to traditional open cholecystectomy in the management of cholelithiasis. It has several advantages .Pneumoperitoneum and trendelenburg positioning causes release of stress hormones and ultimately changes in hemodynamic parameters. Stretching of peritoneum, abdominal wall associated with postoperative pain. So maintenance of haemodynamic stability, immediate postoperative pain control continues to be a major challenge for the anaesthesiologists.
\end{abstract}

Methods: Sample was selected by non-probability sampling technique in two groups distributed as- Group-L (Laparoscopic cholecystectomy, $n=30$ ) and Group-O (opencholecystectomy, $n=30$ ). Detailed history taking, physical examination and routine lab investigations were done. Approval of the study was obtained by the local Ethical Committee. Post-operative complications, postoperative pain, frequency and pattern of cardiovascular complications, frequency and pattern of respiratory complications were evaluated and compared between thegroups

Result: In both groups female were predominant. In this study haemodynamic status (Heart rate, $S B P, D B P, M B P$ ) in different phases of anaesthesia, surgery and postoperative follow-up (at $4^{\text {th }}$ hour, $8^{\text {th }}$ hour, and 12th hour) has been observed.

Conclusion: This study confirms the feasibility and safety of laparoscopic cholecystectomy is better than open technique in terms of attenuation of better haemodynamic stability, better postoperative pain control and less requirement of analgesia.

Key words: Laparoscopic cholecystectomy, Haemodynamic consequences, postoperative period, Open cholecystectomy.

J Dhaka Med Coll. 2019; 28(2) : 184-189

\section{Introduction:}

Laparoscopic technique has emerged as a popular alternative to traditional open cholecystectomy in the management of cholelithiasis. It is nowadays a common dailyperformed procedure worldwide, replacing many types of open surgeries ${ }^{1}$. In 1985, Muhe performed the first laparoscopic cholecystectomy in Germany. But his initial report was largely ignored. In 1987, PhillipeMouret, a French gynaecologist, who is now considered as the pioneer, performed a laparoscopic cholecystectomy and few months later showed a videotape of his technique in Paris. Laparoscopic cholecystectomy is now firmly established as the treatment of choice for patients with symptomatic gall stone diseases. Although providing excellent outcome results, laparoscopic cholecystectomy also induces particular pathophysiological and haemodynamic changes in response to pneumoperitoneum. Knowledge of the pathophysiology of a $\mathrm{CO}_{2}$ pneumoperitoneum can help minimize complications while profiting

1. Dr. Mst. Sabiha Banu, Senior medical officer, TMSS medical college, Bogura.

2. Dr. Mohammmad Shaddam Hoshain Mondol, Anesthesiologist. Dept. of Anesthesia, analgesia, palliative and intensive care medicine $\mathrm{DMCH}$

3. Dr. Rajat Shuvra Das, Specialist, Department anesthesia, BRB Hospital 1td. Panthopath, Dhaka.

4. Dr. Md. Arman Ali, Anesthesiologist, Dept. of anesthesia, analgesia, palliative and intensive care medicine, DMCH

5. Dr. Ishrat Jhahan Shathi, Assistant prof. conservative dentistry and endodontic, SSMC.

6. Dr. Mst. Habiba Khatun, Associate Professor, Department of Radiology and Imaging, BSMMU, Dhaka

7. Dr. Kazi Monisur Rahman, Assistant Professor, Department of Gastroenterology, BSMMU, Dhaka

Correspondence: Dr. Mst. Sabiha Banu, Senior Medical Officer, TMSS Medical College Bogura. Emaildr.sabihabanu@gmail.com, Mobile-01706362485. 
from the benefits of laparoscopic cholecystectomy without concerns about its safety. The $\mathrm{CO}_{2}$ pneumoperitoneum induces hemodynamic, pulmonary, renal, splanchnic and endocrine pathophysiological changes. Most of them are not clinically significant if appropriate anesthetic care is provided. In some cases complications can develop depending on intraabdominal pressure, the amount of $\mathrm{CO}_{2}$ absorbed, the circulatory volume of the patient, the ventilation technique used, the underlying pathologic conditions, and the type of anesthesia. Adequate monitoring and correct management is important to prevent the development of complications especially cardiorespiratory.

Visual clarity, space to perform diagnostic and therapeutic procedures and maintenance of a normal physiologic state is required for safe effective surgery. To perform laparoscopic procedures the abdominal cavity is inflated with gas to create the pneumoperitoneum ${ }^{5}$. Pneumoperitoneum is associated with altered cardiac and pulmonary physiology which may cause significant complications. The raised intra-abdominal pressure of the pneumoperitoneum, alteration in the patient's position and effects of carbon dioxide absorption cause changes in physiology, especially within the cardiovascular and respiratory systems ${ }^{8}$. Pneumo-peritoneum causes significant changes in haemo-dynamic parameters, reflecting in different studies recently, especially in co-morbid patients. Ultimately the consequences of these changes in haemo-dynamic status clinically manifest as cardio- respiratory complications at the postoperative period.

The gas most commonly used for creation of pneumoperitoneum is carbon dioxide $\left(\mathrm{CO}_{2}\right)$. The $\mathrm{CO}_{2}$-induced pneumoperitoneum exerts its physiological effects via two different mechanisms: Mechanical effects relating to increased intraperitoneal pressure and chemical effect of $\mathrm{CO}_{2}$ used for insufflation. The pneumoperitoneum leads to an increase in the intra- abdominal pressure with a consequent elevation of the diaphragm. This results in collapse of basal lung tissue ultimately causing decreased functional residual capacity (FRC), ventilation perfusion ratio $(\mathrm{V} / \mathrm{Q})$ mismatch, increase intrapulmonary shunting of blood which all lead to hypoxemia and increased alveolar arterial oxygen gradient. These consequences can be managed by increased frequency of mechanical ventilation with mild positive end-expiratory pressure (PEEP) and also by increasing fraction of inspired oxygen $\left(\mathrm{FiO}_{2}\right)$ during laparoscopic surgery .

The hemodynamic changes due to position are most significant at the initiation of pneumoperitoneum and near the end of the laparoscopic surgery. The adverse effects of pneumoperitoneum on cardiac performance are due to decreased venous return (cardiac preload), increased systemic vascular resistance (afterload), or both ${ }^{7}$. Many pharmacological techniques are introduced either in the premedication or during induction to attenuate the haemodynamicpressor response, but results were controversial. More attention is given to the use of selective beta-adrenergic blockers to prevent the reflex sympatho-adrenal dischargemediated tachycardia and hypertension during laryngoscopy and intubation. Hypotensive agents, including sodium nitroprusside, nitroglycerine, adrenoreceptor blockers, calcium channel blockers and opioids, have been used effectively to attenuate these haemodynamic responses ${ }^{4}$.

\section{Materials \& methods:}

Sample was selected by non-probability sampling technique in two groups distributed as- Group-L (Laparoscopic cholecystectomy, $\mathrm{n}=30$ ) and Group-O (open cholecystectomy, $\mathrm{n}=30$ ). Detailed history taking, physical examination and routine lab investigations were done. Approval of the study was obtained by the local Ethical Committee. Post-operative complications, post-operative pain, frequency and pattern of cardiovascular complications, frequency and pattern of respiratory complications were evaluated and compared between the groups. All the information's were recorded in data collection sheet. All collected questionnaire were checked very carefully to identify the error in the data. Data processing work was consisted of registration schedules, 
editing computerization, preparation of dummy table, analyzing and matching ofdata.

\section{Result:}

In this study, Mean age of the patients was $35.19 \pm 11.13$ years and $34.50 \pm 9.43$ in Group$\mathrm{L}$ and Group-O respectively. In both groups female were predominant. Male were 9(30.0\%) and female were $21(70.0 \%)$ in Group-L, similarly male were $13(43.3 \%)$ and female were $17(56.7 \%)$ in Group-O.

\section{Table 3.1}

Distribution of patients according to demographic characteristics in both groups $(n=60)$

\begin{tabular}{lccc}
\hline $\begin{array}{l}\text { Frequency } \\
\begin{array}{l}\text { Demographic } \\
\text { variable }\end{array}\end{array}$ & Group-L & Group-O p value \\
\hline Age (year) & $35.19 \pm 11.13$ & $34.50 \pm 9.43$ & 0.810 \\
Gender & $(18-56)$ & $(19-53)$ & 0.532 \\
Male & $9(30.0 \%)$ & $13(43.3 \%)$ & \\
Female & $21(70.0 \%)$ & $17(56.7 \%)$ & \\
\hline
\end{tabular}

Mean age of the patients was $35.19 \pm 11.13$ years and $34.50 \pm 9.43$ in group- $\mathrm{L}$ and group-O respectively. In both groups female were predominant. Male were $9(30.0 \%)$ and female were $21(70.0 \%)$ in group-L, similarly male were $13(43.3 \%)$ and female were $17(56.7 \%)$ in group$\mathrm{O}$. There were no significant differences in age and gender between twogroups.

In this study haemodynamic status (Heart rate, SBP, DBP, MBP) in different phases of anaesthesia, surgery and postoperative followup (at $4^{\text {th }}$ hour, $8^{\text {th }}$ hour, and 12th hour) etc. evaluated. Here it has been reflected that systolic and diastolic blood pressure fluctuated more frequently in case of Group-O in contrast to Group-L at different stages. In case of systolic blood pressure, Mean \pm SD in Group-L and Group-O were 134 \pm 3.0 (baseline value

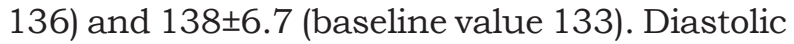
blood pressure, Mean \pm SD in Group-L and Group-O were $80 \pm 2.7$ (baseline value 81 ) and $81 \pm 3.9$ (baseline value 82) respectively. An overall increase in blood pressure has been observed after induction of anaesthesia in both groups, but just at extubation, a gradual fall of blood pressure has been recorded. Here P value was insignificant result statistically. It reflects that there is no marked differences in results between these two groups. Haemodynamic response in terms of MAP and HR have been suggested that MAP and HR remained more stable in Group-L than in Group-O, but the ultimate response in both groups were within the normal range in course of anaesthesia, surgery and in postoperative period.

Table 3.2

Distribution of patients according to blood pressure (SBP, DBP) status in both groups $(n=60)$

\begin{tabular}{|c|c|c|c|c|c|c|}
\hline \multirow[t]{2}{*}{ Time of measurement } & \multicolumn{2}{|c|}{$\mathrm{SBP}^{*}$ (Mean) } & \multirow[t]{2}{*}{ P-value } & \multicolumn{2}{|c|}{$\mathrm{DBP}^{* *}$ (Mean) } & \multirow[t]{2}{*}{ P-value } \\
\hline & Group L & Group O & & Group L & Group O & \\
\hline Baseline & 136 & 133 & & 81 & 82 & \\
\hline At intubation & 141 & 145 & & 85 & 88 & \\
\hline After incision & 137 & 146 & & 82 & 84 & \\
\hline At extubation & 135 & 148 & & 80 & 79 & \\
\hline At 4th hour & 133 & 140 & & 79 & 80 & \\
\hline At 8th hour & 135 & 135 & 0.0786 & 78 & 75 & 0.2051 \\
\hline At 12 th hour & 131 & 140 & & 78 & 82 & \\
\hline Mean & 134 & 138 & & 80 & 81 & \\
\hline SD & 3.0 & 6.7 & & 2.7 & 3.9 & \\
\hline$($ Mean \pm SD) & $134 \pm 3.0$ & $138 \pm 6.7$ & & $80 \pm 2.7$ & $81 \pm 3.9$ & \\
\hline
\end{tabular}

*SBP means systolic blood pressure, **DBP means diastolic blood pressure. 
Hypoxia in terms of percentage saturation of Oxygen $\left(\% \mathrm{SaO}_{2}\right)$ has been observed that $\% \mathrm{~S}_{\mathrm{a}} \mathrm{O}_{2}$ fluctuated more in Group-O than in Group-L. Although there found an abrupt fall of $\% \mathrm{SaO}_{2}$ in Group-L soon after extubation, probably due to hypercarbia or hypoxaemia. Pain is an important confounding variable in this study, as inadequate postoperative control may lead to gross fluctuation and change in haemodynamic parameters (SBP, DBP, MSAP, $\mathrm{HR}$ and $\left.\% \mathrm{SaO}_{2}\right)$.

Table 3.5

Postoperative VAS score in both studied groups. $(n=60)$

\begin{tabular}{lccc}
\hline Group of patients & Group-L & Group-O & $\mathrm{p}$ \\
\hline & $\begin{array}{c}\text { Mean } \pm \text { SD } \\
\text { (Min-Max) }\end{array}$ & $\begin{array}{c}\text { Mean } \pm \text { SD } \\
\text { (Min-Max) }\end{array}$ & value \\
\hline Post operative VAS & $1.94 \pm 0.80$ & $2.34 \pm 1.26$ & \\
After 4 hours & $(0-4)$ & $(0-6)$ & 0.002 \\
& $1.57 \pm 0.94$ & $3.34 \pm 1.26$ & \\
After 8 hours & $(0-4)$ & $(0-6)$ & 0.001 \\
\hline
\end{tabular}

The day before surgery patients were instructed about the Visual Analog Scale (VAS) in which $0=$ no pain and $10=$ worst pain imaginable. VAS was significantly higher after 4 hours, 8 hours, 12 hours and 24 hours in group-O than that of $\mathrm{L}$ groups. There is a gradual fall of pain in the postoperative period. It declined from 1.94 at $4^{\text {th }}$ postoperative hour to 1.08 after 24 hour in group-L, whereas in group-O, it was 2.34 to 2.23 at the respective point of time.

The average postoperative pain (at $4^{\text {th }}, 8^{\text {th }}, 12^{\text {th }}$, $24^{\text {th }}$ hour and at discharge) has been evaluated in terms of visual analogue scale (VAS, 01-10). VAS was significantly higher after 4 hours, 8 hours, 12 hours and 24 hours in Group-O than that of Group-L. There is a gradual fall of pain in the postoperative period. It declined from 1.94 at $4^{\text {th }}$ postoperative hour to 1.08 after 24 hour in Group-L, whereas in Group-O, it was 2.34 to 2.23 at the respective point of time.

\section{Discussion:}

This study aimed to compare the haemodynamic effects in immediate postoperative period of open cholecystectomy \& laparoscopic cholecystectomy. This study was conducted among the 60 patients of elective cholecystectomy over a period of six months at Shaheed Ziaur Rahman Medical College Hospital, Bogura.

Laparoscopy is deemed as a "minimally invasive" procedure that allows for exploration through an endoscope of the peritoneal cavity (Burkun JS et al. 2012). Benefits include reduced postoperative pain,improved cosmetic results and patient satisfaction, and reduced hospital stays. Tissue trauma is significantly less than that with conventional open procedures, thus results in the additional benefit of reduced post-operative pain (Nagle AP et al. 2007).

In this study, Mean age of the patients was $35.19 \pm 11.13$ years and $34.50 \pm 9.43$ in group- $L$ and group-O respectively. In both groups female were predominant. Male were $9(30.0 \%)$ and female were $21(70.0 \%)$ in group-L, similarly male were $13(43.3 \%)$ and female were $17(56.7 \%)$ in group-O. There were no significance differences between two groups ( $>00.05)$. Our study is consistent with the study of Maitra TK et al (2017) and Dexter SP et al (2009). ${ }^{97,87}$

This study reveals, in case of systolic blood pressure, Mean \pm SD in Group-L and Group-O were $134 \pm 3.0$ (baseline value 136) and $138 \pm 6.7$ (baseline value 133) respectively. In case of diastolic blood pressure, Mean \pm SD in Group-L and Group- O were 80 \pm 2.7 (baseline value 81) and $81 \pm 3.9$ (baseline value 82 ) respectively. $\mathrm{P}$ value suggests statistically insignificant results in both values. This study is consistent to a study by Faruquzzaman et al (2016) in BIRDEM General Hospital, Dhaka, among the patients of routine laparoscopic cholecystectomy, similar pattern of changes in SBP and DBP were recorded in different phages of anaesthesia and in postoperative period. ${ }^{98}$ No major difference was observed.

This study shows that mean arterial pressure (MAP) and Heart rate (HR) fluctuated more in different phases in Group-O in contrast to Group-L. Mean \pm SD of MAP and HR in respective groups were $99 \pm 1.4$ (baseline value 99) and $78 \pm 2.8$ (baseline value 84 ) in Group-L, whereas 
in Group-O, these were $100 \pm 2.5$ (baseline value 101) and 80 \pm 5.1 (baseline value 79 ) where $P$ values were 0.3607 and 0.3270 respectively which represents insignificant results. Most of the internationally acceptable researches by Haydon GH et al (2006), Muelett CE et al (2013), Puri GD et al (2002) and Wahba RWM et al (2013) reported almost same pattern of changes in haemodynamic parameters (e.g., heart rate $\&$ mean arterial pressure). These changes occurred in response to pneumoperitoneum for laparoscopic cholecystectomy ${ }^{75,82-84}$. Hence haemodynamic status is good in laparoscopic surgery which is similar with our result.

Moreover nausea/vomiting were observed significantly higher in group-L (16.7\%) whereas abdominal pain was observed significantly higher in group-O (23.3\%). Even though urinary retention, hypotension and headache were found higher in group-O than that of group-L. But there was no significant difference between these two groups.Joris et al. (2013), reported similar complication of nausea $\&$ vomiting in $35 \%$ patients. ${ }^{13}$

Furthermore, percentage saturation of Oxygen $\left(\mathrm{SaO}_{2}\right)$ after extubation revealed that fall and fluctuation were more pronounced in Group-L than in group-O.Zacks et al (2002) reported that the incidence of hypoxia in perioperative period found relatively higher (approximately 12.5\%) in response to pneumoperitoneum for laparoscopic surgery. So our study consistent with the study of Zacks et al (2002). ${ }^{70}$

In this study pain was assessed according to VAS score. There is a gradual fall of pain in the postoperative period. It declined from 1.94 at $4^{\text {th }}$ postoperative hour to 1.08 after 24 hour in Group-L, whereas in Group-O, it was 2.34 to 2.23 at the respective point of time. Study by Pucci et al (2009), Pelosi et al (2006) and Lewis et al (2012) demonstrated that average level of pain and tenderness were significantly higher open cholecystectomy, most possibly due to excessive stress response in such patients $67,72,80$.

The study reveals need for use of rescue medication (Inj. Pethidine) was more in group$\mathrm{O}(73.6 \pm 15.9)$ than in group-L $(52.4 \pm 12.4)$ and the difference was statistically significance $(\mathrm{p}<0.05)$.

We also found that duration of anaesthesia as well as duration of surgery was higher in Group$\mathrm{L}(45.50 \pm 5.33$ minute and $36.84 \pm 4.46$ minute) than that of group-O (41.38 \pm 5.03 minute and $34.50 \pm 5.34$ minute) but the difference was not statistically significant $(p>0.05)$. Duration of post operative hospital stay was significantly higher in group-O $(4.46 \pm 0.94$ days $)$ than that of group-L (2.61 \pm 0.57 days), difference was statistically significant $(\mathrm{p}<0.05)$.

\section{Conclusions:}

Laparoscopic cholecystectomy has been established as the gold standard for management of cholelithiasis. Present study established that haemodynamic consequences in immediate postoperative period were better in laparoscopic group than open. This study confirms the feasibility and safety of laparoscopic cholecystectomy is better than open technique in term of attenuation of better haemodynamic stability, better post operative pain control and less requirement of analgesia. Although fluctuation in haemodynamic parameters (systolic and diastolic blood pressure, mean arterial pressure, heart rate and percentage saturation of Oxygen) are more frequent in the intubation, extubation period of laparoscopic cholecystectomy, but the overall postoperative cardio-pulmonary outcomes remains almost stabilized. Although the duration of surgery and duration of anaesthsia is slightly higher in patients with group-L, but the results in the both groups to such relation are comparable which is reflected in the almost same duration. But overall hospital stay, post surgical ward was significantly lower in groupL. The ultimate results of this study is highly suggestive of that routine laparoscopic cholecystectomy is a safe and resilient procedure for the cholecystectomy surgery

\section{References;}

1. Litynski GS. The laparoscopic breakthrough in Europe. JSLS.2009;3(2):163-167.

2. Barkun JS, Barkun AN, Sampalis JS, et al. Randomised controlled trial of laparoscopic versus mini cholecystectomy. The McGill Gallstone Treatment group. Lancet.2012; 340(8828):11161119. 
3. Nagle AP, Soper NJ, Hines JR. Zinner MJ, Ashley SW. Maingot's abdominal operations. New York: McGraw-Hill Medical. 2007847-863.

4. Rosentha RJ, Szomstein S, Kennedy CI, Soto FC, Zundel N. Laparoscopic surgery for morbid obesity: 1001 consecutive bariatric operations performed at the Bariatric Institute, Cleveland Clinic Florida. Obes Surg.2006;16(2):119-124.

5. Doste K, Lacoste L, Lehuede KJ, MS TD, Fusciardi J. Haemodynamic and ventricular changes during laparoscopic cholecystectomy in elderly ASA III patients. Can J Anaesthesia.2016;43(8):783-788.

6. Barone JE, Bears S, Chen S, et al. Outcome study of cholecystectomy during pregnancy. Am J Surg.2009;177:232-236.

7. McLaughlin JG, Scheeres DE, Dean RJ, Bonnel BW. The adverse hemodynamic effects of laparoscopic cholecystectomy. SurgEndosc.2015;9:121-124.
8. Glaser F, Sanwald GA, Buhr HJ, et al. General stress response to conventional and laparoscopic cholecystectomy. Ann Surg.2005;221:372-380.

9. Joris J, Cigarini I, Legrand M, et al. Metabolic and respiratory changes after cholecystectomy performed via laparotomy or laparoscopy. $\mathrm{Br} \mathrm{J}$ Anaesth.2002;69:341-345.

10. Kloosterman T, von Blomberg BME, Borgstein P, et al. Unimpaired immune functions after laparoscopic cholecystectomy. Surgery.2004;115:424-428.

11. Hsieh $\mathrm{CH}$. Laparoscopic cholecystectomy for patients with chronic obstructive pulmonary disease. Laparoendosc Adv Surg Tech2013;13:5-9.

12. Neudecker J, Sauerland S, Neugebauer E, Bergamaschi R, Bonjer HJ, et. al. The EAES clinical practice guidelines on pneumoperitoneum for laparoscopic surgery. SurgEndosc 2012;16:11211143.

13. Joris JL, Noirot DP, Legrand MJ, Jacquet NJ, Lamy ML. Hemodynamic changes during laparoscopic cholecystectomy. AnesthAnalg2013;75:1067-1071. 